\title{
Early Predictors of Left Ventricular Remodeling after Primary Percutaneous Coronary Intervention
}

\author{
MOHAMED KASEM ALI, M.Sc.; MAHMOUD ABD EL-SABOUR, M.D.; HAMDY SHAMS-EDDIN and \\ AMR A.A. YOUSSEF, M.D.
}

The Department of Cardiovascular Medicine, Faculty of Medicine, Assiut University, Assiut, Egypt

\begin{abstract}
Background: Successful primary Percutaneous Coronary Intervention (PCI), has reduced the mortality of patients with Acute Myocardial Infarction (AMI). However, the increased survival rate resulted in the increased incidence of Left Ventricular (LV) remodeling. Ventricular remodeling is a predictor of heart failure and for this reason it assumes a negative prognostic value.
\end{abstract}

Aim of the Study: Was to assess the percentage of LV remodeling and to identify at discharge early predictors of LV remodeling after primary PCI.

Material and Methods: We included 152 patients diagnosed as acute STEMI and underwent successful primary PCI. All patients were examined by transthoracic echocardiography at discharge and 6 months later. LV remodeling defined as increase in Left Ventricular End Diastolic Volume Index (LVEDVI) $>20 \%$. Patients were grouped into two groups: Group I (with LV remodeling) and Group II (without LV remodeling). The following factors affecting LV remodeling were evaluated: Infarct Related Artery (IRA), number of vessels affected, use of thrombus aspiration, type of stent used, post PCI TIMI flow, time to reperfusion, Wall Motion Score Index (WMSI) and cardiovascular risk factors.

Results: Patients with an increase in LVEDVI $>20 \%$ who were considered to have LV remodeling (Group I) were 49 patients $(32.2 \%)$. Anterior MI was significantly more in Group I patients $(89.8 \%)$ vs. $(44.7 \%)$ in Group II patients ( $p$-value= $0.00)$. Left Anterior Descending (LAD) artery affection was significantly more in Group I (89.8\%) vs. (45.6\%) in Group II $(p$-value $=0.00)$. Ejection fraction noticed to be significantly greater at baseline in Group II $(51 \pm 6.81 \%)$ vs. $(41.4 \pm 6.59 \%)$ in Group I ( $p$-value $=0.00)$ while Group I patients had significant higher WMSI $(1.66 \pm 0.19)$ vs. $(1.28 \pm 0.17)$ in Group II ( $p$-value $=0.00)$.

Conclusions: LV remodeling occurred in $32.2 \%$ of patients. Patients with ECG diagnosis as (anterior MI), WMSI ( $>1.5$ ), ejection fraction $(\leq 45 \%)$, and LAD as an IRA were at higher risk for LV remodeling $(p<0.05)$. WMSI $(>1.5)$ and LAD as an IRA were the only independent predictors for LV remodeling after primary PCI (relative risk; 3.2 and 2.6 respectively).

Correspondence to: Dr. Mohamed Kasem Ali, The Department of Cardiovascular Medicine, Faculty of Medicine, Assiut University, Assiut, Egypt
Key Words: Predictors of LV remodeling - Acute myocardial infarction - Primary PCI.

\section{Introduction}

ACUTE Myocardial Infarction (AMI) with its accompanying adverse sequelae, remains one of the most common causes of morbidity and mortality in the world [1].

Reperfusion therapy is by far the most important therapy for the treatment of AMI. Reperfusion of the ischemic myocardium reduces the infarct size and improves Left Ventricular (LV) function, both of which contribute to an improved clinical outcome in patients with acute MI [2].

The success of fibrinolytic therapy and more recently of primary Percutaneous Coronary Intervention (PCI), has reduced the mortality of patients with acute MI [3]. However, the increased survival rate resulted in the increased incidence of cardiovascular events mainly due to LV remodeling and congestive heart failure [4]

Cardiac remodeling is a group of molecular, cellular and interstitial changes that clinically manifest as changes in size, shape and function of the heart resulting from cardiac injury [5]

Post-infarct ventricular remodeling develops in about $30 \%$ of patients with a history of myocardial infarction [6]. Ventricular remodeling is a predictor of heart failure and for this reason it assumes a negative prognostic value [7].

The pathogenesis of LV remodeling after acute M1 is multi-factorial. Multiple factors may in fact contribute at different stages from the time of coronary occlusion until the development of ventricular dilatation [2] . 
There are clinical evidences that post-infarct remodeling can be prevented or in some cases reversed [8]

Therapies with proven efficacy against postinfarct remodeling exist and research is bringing new discoveries in the pathogenesis of post-infarct remodeling into the field of clinical practice and therapy [9]. For this reason, the battle of medicine against heart failure is against post-infarct remodeling which means that the prevention is better than the cure.

Infarct size, anterior location, the perfusion status of the Infarct-Related Artery (IRA), a restricted pattern of LV filling and heart failure on admission have been identified as predictors of $\mathrm{LV}$ remodeling after $\mathrm{MI}$ in the thrombolysis era [10].

Recently there has been increased interest in the prevalence of remodeling in th $1 \mathrm{e}$ era of interventional cardiology. From a clinical point of view it is important to identify those patients at high risk for LV remodeling. The early identification of patients at a risk of $\mathrm{LV}$ remodeling may have important therapeutic implications [11]

The factors predicting post-infarct LV remodeling after MI treated by primary PCI remain to be clarified.

The aim of the study was to assess the percentage of LV remodeling and to identify at discharge early predictors of $\mathrm{LV}$ remodeling after primary PCI.

\section{Material and Methods}

We conducted a prospective observational study in which we included 152 patients diagnosed as acute STEMI and admitted in Coronary Care Unit (CCU) of Assiut University Hospital between 1 st January 2016 and 30 th September 2016.

- All patients were treated by successful primary PCI within 12 hours of onset of chest pain or up to 24 hour of onset of chest pain if there was ongoing ischemia at Assiut University Hospital Cath laboratory.

-We excluded patients with clinical manifestations of acute heart failure or cardiogenic shock at presentation, significant mitral regurgitation or valve disease and patients with permanent pacemaker insertion.

- Detailed history was obtained from all patients including age, gender, cardiovascular risk factors (hypertension, diabetes mellitus, smoking and dyslipidemia) and onset of chest pain

- 12 lead electrocardiogram (ECG) was done to all patients within 10 minutes of arrival to Emergency Room (ER) and after primary PCI.

- Echocardiography: All patients were examined by transthoracic $2 \mathrm{D}$ echocardiography within 24 hour of admission and six months after discharge using Phillips i.e 33 ultrasound system device according to the following protocol:

1- LV volumes (LVEDV and LVESV) and Ejection Fraction (EF) were measured using modified Simpson's method.

Volume measurements are usually based on tracings of the blood-tissue interface in the apical four-chamber (A4C) and two-chamber (A2C) views. At the mitral valve level, the contour is closed by connecting the two opposite sections of the mitral ring with a straight line. The most commonly used method for 2D echocardiographic volume calculations is the biplane method of disks summation (modified Simpson's rule) Fig. (1) [12]

Biplano disk summation

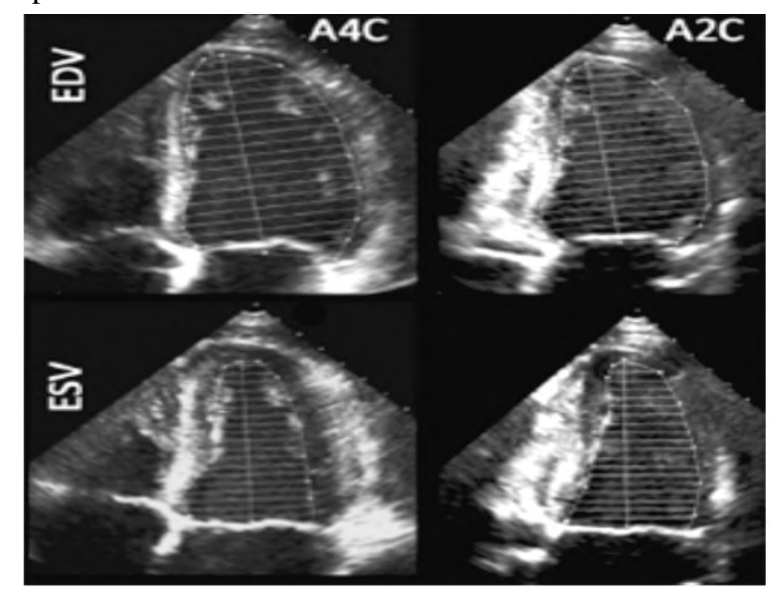

Fig. (1): Modified Simpson's method for assessment of LV volumes [12]

A4C : Apical four Chamber

A2C : Apical two Chamber.

EDV : End-diastolic Volume. ESV : End-Systolic Volume.

2- Wall Motion Score Index (WMSI) was calculated as follows: The LV was divided according to a 17-segment model. A wall motion score was assigned to each segment to calculate the LV wall motion score index as the average of the scores of all segments visualized.

The following scoring system was used: Normal or hyperkinetic scored (1), hypokinetic (reduced thickening) scored (2), akinetic (absent or negligible thickening, e.g. scar) scored (3), and dyskinetic (systolic thinning or stretching, e.g., aneurysm) scored (4) [12]. 


$$
\text { WMSI }=\frac{\text { Sum of scores of all segments visualized }}{\text { Number of these segments }}
$$

3- Pulsed Wave (PW) Doppler of trans-mitral flow during diastole to assess LV diastolic filling pattern. The following variables were calculated at baseline: Peak velocity of early rapid filling wave (E), peak velocity of atrial wave (A), peak E/A wave velocity ratio and Deceleration time (DT). Valsalva maneuver was done if needed to confirm grade of diastolic dysfunction [13].

The selected patients were grouped into two groups after 6 months of MI:

- Group I (with LV remodeling): Patients with an increase in LVEDVI $>20 \%$ were considered to have $L V$ remodeling.

An arbitrary definition of ventricular remodeling, but widely adopted in follow-up studies $[11,14,15]$, is an increase of at least $20 \%$ of LVEDV from the first post infarction imaging.

- Group II (without LV remodeling).

So the percentage of patients who developed progressive LV remodeling after 6 months was detected.

Then the following factors and their influence on $L V$ remodeling were evaluated in each group:

A- Clinical: Age, gender, risk factors (Diabetes Mellitus (DM), Hypertension (HTN), Dyslipidemia, Smoking).

B- ECG diagnosis and location of STEMI.

\section{C-Angiographic:}

- Type of IRA (Left Anterior Descending (LAD), Left Circumflex (LCX) or Right Coronary Artery (RCA).

- Number of vessels affected.

- Thrombus aspiration.

- Symptom to balloon time $>4$ hours.

- Stenting and type of the stent (Drug Eluting Stent (DES) or Bare Metal Stent (BMS).

- Post PCI TIMI flow grade.

D- Echocardiographic:

- LVEDVI $\left[\mathrm{ml} / \mathrm{m}^{2}\right]$.

- LVESVI $\left[\mathrm{ml} / \mathrm{m}^{2}\right]$.

- Ejection fraction [\%].

- Wall Motion Score Index (WMSI).

- Grade of diastolic dysfunction.
Informed consents were obtained from all participants after the explanation of all steps of the study. The Ethical Committee of Assiut, Faculty of Medicine approved the study protocols.

\section{Statistical analysis:}

All statistical analyses were carried out using Software Package for Social Sciences (SPSS) Version 20.0. Categorical variables were described by number and percent $(\mathrm{N}, \%)$ and continuous variables described by mean and Standard Deviation (mean \pm SD). Chi-square test and Fisher Exact test were used to compare between categorical variables while continuous variables of both groups were compared by Student $t$-test. Differences in echocardiographic variables (baseline vs. six months) were assessed by paired $t$-test. In order to predict LV remodeling in an individual patient clinical, angiographic and echocardiographic variables were put into logistic regression analysis.

Variables with statistical significance at univariate analysis were further analyzed at multivariate analysis. A $p$-value $<0.05$ was considered statistically significant.

\section{Results}

The current study included 152 patients who were diagnosed as acute STEMI treated by primary PCI, within 12 hours of onset of chest pain or up to 24 hour of onset of chest pain if there is ongoing ischemia at Assiut University Hospital Cath lab. Patients with an increase in LVEDVI $>20 \%$ who considered to have LV remodeling (Group I) were 49 patients $(32.2 \%)$ while the other patients without LV remodeling were 103 patients $(67.8 \%)$ and known as (Group II). Regarding age, gender, smoking, risk factors, and previous history of PCI, there was no statistically significant difference between the two groups ( $p$-value $>0.05)$. Regarding electrocardiographic data, it was noticed that anterior MI was significantly more in Group I patients ( $p$-value $=0.00$ ) while inferior MI were significantly more in Group II patients ( $p$-value $=0.00)$.

Regarding angiographic data, there was a significant difference between both groups regarding Infarct Related Artery (IRA) with significant more affection of Left Anterior Descending (LAD) artery in Group I patients ( $p$-value $=0.00)$, and significant more affection of Right Coronary Artery (RCA) and Left Circumflex (LCX) arteries in Group II patients $(p$-value $=0.00)$. Other angiographic findings regarding number of vessels affected, use of thrombus aspiration, type of stent and post PCI TIMI grade had no significant sta- 
tistical difference between both groups ( $p$-value in all >0.05) (Table 1).

Table (1): Baseline angiographic findings of both groups.

\begin{tabular}{|c|c|c|c|}
\hline Variables & $\begin{array}{l}\text { Group I } \\
(\mathrm{n}=49)\end{array}$ & $\begin{array}{l}\text { Group II } \\
(\mathrm{n}=103)\end{array}$ & $\begin{array}{c}p- \\
\text { value }\end{array}$ \\
\hline $\begin{array}{l}\text { Infarct related artery: } \\
\text { - Left anterior descending (LAD) } \\
\text { - Right coronary artery (RCA) } \\
\text { - Left circumflex artery (LCX) }\end{array}$ & $\begin{array}{ll}44 & (89.8 \%) \\
3 & (6.1 \%) \\
2 & (4.1 \%)\end{array}$ & $\begin{array}{ll}47 & (45.6 \%) \\
43 & (41.7 \%) \\
13 & (12.6 \%)\end{array}$ & 0.00 \\
\hline $\begin{array}{l}\text { Number of vessels affected: } \\
\text { - Single vessel } \\
\text { - Two vessels } \\
\text { - Three vessels }\end{array}$ & $\begin{array}{ll}30 & (61.2 \%) \\
13 & (26.5 \%) \\
6 & (12.2 \%)\end{array}$ & $\begin{array}{l}54(52.4 \%) \\
32(31.1 \%) \\
17(16.5 \%)\end{array}$ & 0.57 \\
\hline $\begin{array}{l}\text { Thrombus aspiration: } \\
\text { - Yes } \\
\text { - No }\end{array}$ & $\begin{array}{l}10(20.4 \%) \\
39(79.6 \%)\end{array}$ & $\begin{array}{ll}21 & (20.4 \%) \\
82 & (79.6 \%)\end{array}$ & 0.89 \\
\hline $\begin{array}{l}\text { Stenting: } \\
\text { - Yes } \\
\text { - Drug eluting stent (DES) } \\
\text { - Bare metal stent (BMS) } \\
\text { - No }\end{array}$ & $\begin{array}{ll}48 & (98 \%) \\
7 & (14.3) \\
41 & (83.7) \\
1 & (2 \%)\end{array}$ & $\begin{array}{l}93(90.3 \%) \\
20(19.4) \\
73(80.9) \\
10(9.7 \%)\end{array}$ & 0.31 \\
\hline Symptoms to balloon time $\geq 4 \mathrm{~h}$ & $33(67.3 \%)$ & $60(58.3 \%)$ & 0.18 \\
\hline Post PCI TIMI grade >2 & $46(93.9 \%)$ & $100(97.1 \%)$ & 0.29 \\
\hline
\end{tabular}

PCI: Percutaneous Coronary Intervention.

Regarding baseline echocardiographic data, there was no statistically significant difference between both groups regarding grade of diastolic dysfunction ( $p$-value $>0.05)$.

Group I patients had significantly higher LVEDVI and LVESVI in comparison with Group II $(p$ - value $=0.01,0.00)$ respectively. Ejection fraction noticed to be significantly greater in Group II patients $(51 \pm 6.81 \%)$ vs. $(41.4 \pm 6.59 \%)$ in Group I patients $(p$-value $=0.00)$ while Group I patients had significant higher WMSI $(1.66 \pm 0.19)$ vs. $(1.28 \pm 0.17)$ in Group II patients $(p$-value $=0.00)$ (Table 2).

Table (2): Baseline echocardiographic characteristics of all studied patients.

\begin{tabular}{lccc}
\hline Variables & $\begin{array}{c}\text { Group I } \\
(\mathrm{n}=49)\end{array}$ & $\begin{array}{c}\text { Group II } \\
(\mathrm{n}=103)\end{array}$ & $\begin{array}{c}p \text { - } \\
\text { value }\end{array}$ \\
\hline LVEDVI $\left(\mathrm{ml} / \mathrm{m}^{2}\right)$ & $62.75 \pm 17.23$ & $53.91 \pm 14.97$ & 0.01 \\
LVESVI $\left(\mathrm{ml} / \mathrm{m}^{2}\right)$ & $33.63 \pm 11.21$ & $25.39 \pm 7.71$ & 0.00 \\
Ejection fraction $(\%)$ & $41.41 \pm 6.59$ & $51 \pm 6.81$ & 0.00 \\
WMSI & $1.66 \pm 0.19$ & $1.28 \pm 0.17$ & 0.00 \\
Grade of diastolic dysfunction: & & & \\
$\quad 1$ & $32(65.3 \%)$ & $65(63.1 \%)$ & 0.46 \\
2 & $17(34.7 \%)$ & $38(36.9 \%)$ & \\
\hline
\end{tabular}

LVEDVI : Left Ventricular End-Diastolic Volume Index. LVESVI : Left Ventricular End-Systolic Volume Index. WMSI : Wall Motion Score Index.

Six months follow-up echocardiographic characteristics of both groups are shown in (Table 3).
It was noticed that Group I patients had significantly higher LVEDVI, LVESVI, and WMSI during 6month follow-up in comparison to Group II patients $(p$-value $<0.05)$.

In contrast, Group II patients had more significant ejection fraction than Group I patients $(p-$ value $<0.05$ ).

Table (3): Six month follow-up echocardiographic characteristics of all studied patients.

\begin{tabular}{llll}
\hline Variables & \multicolumn{1}{c}{$\begin{array}{c}\text { Group I } \\
(\mathrm{n}=49)\end{array}$} & $\begin{array}{c}\text { Group II } \\
(\mathrm{n}=103)\end{array}$ & $\begin{array}{c}p \text { - } \\
\text { value }\end{array}$ \\
\hline LVEDVI $\left(\mathrm{ml} / \mathrm{m}^{2}\right)$ & $90.40 \pm 17.69$ & $55.18 \pm 14.31$ & 0.00 \\
LVESVI $\left(\mathrm{ml} / \mathrm{m}^{2}\right)$ & $42.10 \pm 12.39$ & $26.06 \pm 7.23$ & 0.00 \\
Ejection fraction $(\%)$ & $36.18 \pm 6.66$ & $52.57 \pm 6.38$ & 0.00 \\
WMSI & $1.67 \pm 0.17$ & $1.22 \pm 0.14$ & 0.00 \\
\hline
\end{tabular}

LVEDVI : Left Ventricular End-Diastolic Volume Index.

LVESVI : Left Ventricular End-Systolic Volume Index.

WMSI : Wall Motion Score Index.

Comparison between baseline and 6-months echocardiographic characteristics of both groups (Table 4):

In patients with LV remodeling, LVEDVI and LVESVI were significantly increased, while ejection fraction was significantly decreased $(p<0.00)$ but no significant change occurred in case of WMSI $(p>0.05)$.

In patients without LV remodeling, no significant difference between LVEDVI, LVESVI, ejection fraction and WMSI at baseline and 6-months follow-up $(p>0.05)$.

Table (4): Comparison between baseline and 6-months echocardiographic characteristics of both groups.

\begin{tabular}{|c|c|c|c|}
\hline Variables & Baseline & $\begin{array}{l}\text { 6-months } \\
\text { follow-up }\end{array}$ & $\begin{array}{c}p- \\
\text { value }\end{array}$ \\
\hline \multicolumn{4}{|l|}{ For patients with $L V$} \\
\hline - LVEDVI $\left(\mathrm{ml} / \mathrm{m}_{2}^{2}\right)$ & $62.75 \pm 17.23$ & $90.40 \pm 17.69$ & 0.00 \\
\hline - LVESVI (ml/m²) & $33.63 \pm 11.21$ & $42.10 \pm 12.39$ & 0.00 \\
\hline - Ejection fraction $(\%)$ & $41.41 \pm 6.59$ & $36.18 \pm 6.66$ & 0.00 \\
\hline - WMSI & $1.66 \pm 0.19$ & $1.67 \pm 0.17$ & 0.25 \\
\hline \multicolumn{4}{|l|}{$\begin{array}{l}\text { For patients without } L V \\
\text { remodeling: }\end{array}$} \\
\hline - LVEDVI $\left(\mathrm{ml} / \mathrm{m}_{2}^{2}\right)$ & $53.91 \pm 14.97$ & $55.18 \pm 14.31$ & 0.14 \\
\hline - LVESVI (ml/m²) & $25.39 \pm 7.71$ & $26.06 \pm 7.23$ & 0.93 \\
\hline - Ejection fraction (\%) & $51 \pm 6.81$ & $52.57 \pm 6.38$ & 0.11 \\
\hline - WMSI & $1.28 \pm 0.17$ & $1.22 \pm 0.14$ & 0.09 \\
\hline
\end{tabular}

LVEDVI : Left Ventricular End-Diastolic Volume Index.

LVESVI : Left Ventricular End-Systolic Volume Index.

WMSI : Wall Motion Score Index.

Regression analysis for prediction of $L V$ remodeling following primary PCI:

Regression analysis showed that patients with ECG's diagnosis as (anterior MI), WMSI (>1.5), 
Ejection fraction $(<45 \%)$, and IRA as (LAD) were at higher risk for $\mathrm{LV}$ remodeling $(p<0.05)$ as described in (Table 5).

Multivariate regression analysis of significant predictors showed that WMSI $(>1.5)$ and IRA as (LAD) are only independent predictors for LV remodeling after primary PCI (relative risk; 3.2 and 2.6 respectively).

Table (5): Regression analysis of baseline prediction for remodeling after primary PCI in studied patients.

\begin{tabular}{lccc}
\hline Variables & $\begin{array}{c}\text { Relative } \\
\text { risk }\end{array}$ & $\begin{array}{c}95 \% \\
\text { confidence } \\
\text { interval }\end{array}$ & $\begin{array}{c}p \text { - } \\
\text { value }\end{array}$ \\
\hline ECG's findings (extensive anterior MI) & 1.7 & $1.9-2.55$ & 0.00 \\
LVESVI (ml/m ${ }^{2}$ ) & 2.3 & $1.44-2.4$ & 0.09 \\
LVEDVI (ml/m ${ }^{2}$ ) & 1.1 & $1.1-2.16$ & 0.43 \\
WMSI (>1.5) & 3.2 & $1.44-2.15$ & 0.02 \\
Ejection fraction (545\%) & 2.2 & $2.1-2.88$ & 0.01 \\
Infarct-Related Vessel (LAD) & 2.6 & $1.9-2.23$ & 0.00 \\
\hline
\end{tabular}

ECG : Electrocardiogram.

LAD : Left Anterior Descending.

LVEDVI : Left Ventricular End-Diastolic Volume Index.

LVESVI : Left Ventricular End-Systolic Volume Index.

WMSI : Wall Motion Score Index.

\section{Discussion}

Despite the latest techniques and advances in acute myocardial infarction treatment and management, the post-infarct left ventricular remodeling process that leads to congestive heart failure still represents a major problem [16]

Over the past decades, scientists and healthcare providers have made substantial efforts to improve the understanding of this process by searching bad or good predictors and also risk factors which can be associated with this process.

Two-dimensional (2D) echocardiography is a widely available and well-established method for assessing LV remodeling.

In our study, we used 2D echocardiography to assess LV volumes in patients treated by primary PCI within 24 hour of admission and 6 months later after discharge.

The aim of the study was to assess the percentage of patients who developed progressive LV remodeling after the first 6 months of MI treated with primary PCI. In our study we found that LV remodeling occurred in $32.2 \%$ of patients after 6 months of primary PCI, which was concordant with findings of Bolognese et al., [15] who found that LV dilatation at 6 months with $>20 \%$ increase in LVEDVI, occurred in $30 \%$ of a group of 284 patients undergoing primary PCI for acute MI. Also, concordant with findings of Loboz-Grudzie'n et al., [11] who found that progressive LV dilatation had occurred in $24 \%$ of a group of 88 patients underwent primary PCI for acute MI. Also, a review article published 2011 in European Heart Journal stated that post-infarct ventricular remodeling develops in about $30 \%$ patients with a history of myocardial infarction [6]. The early identification of patients at a risk of $\mathrm{LV}$ remodeling may have important therapeutic implications.

So, in our study we aimed to identify at discharge the clinical, angiographic and echocardiographic predictors of LV remodeling after primary PCI in a group of 152 STEMI patients in Assiut University Hospital.

Regarding clinical data and risk factors, we found that there was no statistically significant difference between group of patients who developed LV remodeling after 6 month and those who didn't develop LV remodeling regarding age, gender and risk factors as HTN, DM, smoking or dyslipidaemia. These findings are consistent with findings of Zaliaduonyte-Peksiene et al., [17] and LobozGrudzie'n et al., [11] who also couldn't also detect a clinical risk factor as a significant predictor of post-infarct LV remodeling. In contrast to findings of Pop et al., [16] who studied predictors of postinfarct LV remodeling in a group of 105 STEMI patient treated by primary PCI and found that risk factors correlated with post-infarct LV remodeling were female gender, smoking and dyslipidaemia. This difference could be due to smaller sample size of Pop et al., [16] study as they studied only 105 patients of whom there were only 27 females (12 females developed LV remodeling and 15 didn't develop remodeling) this represented 52\% in Group 1 vs. $18 \%$ in Group 2, $p<0.00$ and considered as significant predictor while in our study females were 33 (11 developed LV remodeling and 22 didn't develop remodeling), but due to larger sample size this represented $22.4 \%$ in Group I and $21.4 \%$ in Group II ( $p$-value $=0.51$ ). Similarly regarding other risk factors as smoking and dyslipidaemia, difference in results between our study and that of Pop et al., [16] may be attributed to the different sample size.

Regarding electrocardiographic data, in our study we found that patients with anterior location of AMI were at high risk for LV remodeling after AMI by univariate analysis, but in multivariate regression analysis it was not an independent predictor of $\mathrm{LV}$ remodeling. 
These findings are consistent with findings of Zaliaduonyte-Peksiene et al., [17] who studied the impact of clinical, echocardiographic parameters and polymorphism of angiotensinogen gene on left ventricular remodeling after AMI in a group of 141 patients with first STEMI, and found that anterior localization of the infarct, leucocyte count at admission, global longitudinal strain and $\mathrm{MM}$ genotype were independent predictors of LV remodeling after AMI.

Regarding angiographic data, we found no statistically significant difference between both patient groups regarding number of vessels affected, use of thrombus aspiration, type of stent used either BMS or DES and post PCI TIMI flow. But, regarding IRA, patients with LAD as an IRA were at higher risk for $\mathrm{LV}$ remodeling by univariate analysis, and also an independent predictor by multivariate regression analysis.

These findings are consistent with findings of Warren et al., [18] who studied the time course of LV dilatation after AMI and influence of IRA and found that $\mathrm{LV}$ dilatation was more frequent and significantly more marked $(p<0.01)$ in patients with LAD occlusion as compared with RCA occlusion. Also, consistent with findings of LobozGrudzie'n et al., [11] who studied early predictors of adverse LV remodeling after primary angioplasty in 88 patients with first STEMI and found that LAD as IRA was a significant predictor of LV remodeling by univariate regression analysis $(p<0.05)$. But regarding number of vessels affected, our findings were not consistent with findings of Bolognese et al., [15] who studied LV remodeling after primary angioplasty in 284 patients with AMI treated with primary PCI and found that independent predictors of late (after 6 months) LV dilatation were high peak Creatine Kinase (CK) value and the presence of multi-vessel Coronary Artery Disease (CAD). Also not consistent with findings of Pop et al., [16] who studied predictors of postinfarct LV remodeling in a group of 105 STEMI patient treated by primary PCI and found that the presence of multi-vessel coronary artery disease was a significant predictor of LV remodeling.

Regarding echocardiographic data, we found that the baseline LVEDVI and LVESVI were significantly higher in patients who developed LV remodeling. But, neither LVEDVI nor LVESVI was a significant predictor of LV remodeling by univariate regression analysis.

Patients with baseline (at discharge) low LVEF $<45 \%$ and high WMSI $>1.5$ were found to be at higher risk for LV remodeling.
Multivariate regression analysis showed that WMSI $>1.5$ is an independent predictor of $\mathrm{LV}$ remodeling.

Our findings were consistent with findings of Bolognese et al., [15] who studied LV remodeling after primary angioplasty in 284 patients with AMI treated with primary angioplasty and found that high WMSI independently predicted early LV dilatation. Also, consistent with findings of LobozGrudzie'n et al., [11] who also found that high WMSI >1.5 is an independent predictor of LV remodeling after primary angioplasty.

Our study showed no significant difference between both groups regarding grade of diastolic dysfunction. In contrast to finding of Cerisano et al. [19] who studied the relation between early assessment of Doppler-derived mitral deceleration time (DT), a measure of LV compliance and filling, and prediction of progressive LV dilatation after acute myocardial infarction (AMI) and found that DT was the most powerful predictor of LVEDVI changes at 6 months $(p=0.02)$. Also inconsistent with findings of Loboz-Grudzie'n et al., who found that restrictive pattern of LV filling is a significant predictor of LV remodeling. This difference may be attributed to smaller sample size of LobozGrudzie'n et al., [11] study who studied predictors of $\mathrm{LV}$ remodeling in 88 patients.

\section{Study limitations:}

One limitation of our study is that echocardiographic assessment of global left ventricular systolic function is usually performed subjectively. Twodimensional echocardiography does not offer very precise data about the ventricular volumes or the infarct size, it is better to be assessed by Cardiac Magnetic Resonance (CMR) imaging or 3D echocardiography. Another limitation of our study was a lack of knowledge of late IRA patency. We were unable to perform coronary angiography at 6-month follow-up and thus cannot exclude the possibility that recurrent ischemia may have played a role in triggering the remodeling process.

Also, we didn't evaluate myocardial perfusion after primary PCI which may play an important role in development of LV remodeling.

\section{Conclusion:}

Post-infarct LV remodeling occurred in $32.2 \%$ of studied patients. Patients with anterior location of MI, WMSI > 1.5, LVEF < $45 \%$ and LAD as IRA were considered at higher risk for LV remodeling after primary PCI. However, WMSI $>1.5$ and LAD as IRA were only the independent predictors of $\mathrm{LV}$ remodeling after primary PCI. 


\section{Conflicts of interest notification:}

The authors have no conflicts of interest to declare.

\section{Acknowledgments:}

I would like to acknowledge with gratitude the support and love of my family.

Funding:

No funding.

\section{References}

1- GO A.S., MOZAFFARIAN D., ROGER V.L., BENJAMIN E.J., et al.: Heart disease and stroke statistics-2013 update. Circulation, 127 (1), 2013.

2- ROSSINI R., SENNI M., MUSUMECI G., FERRAZZI P. and GAVAZZI A.: Prevention of left ventricular remodelling after acute myocardial infarction: An update. Recent patents on cardiovascular drug discovery, 5 (3): 196-207, 2010.

3- SIMOONS M. and ELLIS S.: A clinical trial comparing primary coronary angioplasty with tissue plasminogen activator for acute myocardial infarction. New England Journal of Medicine, 336 (23): 1621-8, 1997.

4- LUNDE K., SOLHEIM S., AAKHUS S., ARNESEN H., et al.: Intracoronary injection of mononuclear bone marrow cells in acute myocardial infarction. New England Journal of Medicine, 355 (12): 1199-209, 2006.

5- AZEVEDO P.S., POLEGATO B.F., MINICUCCI M.F., PAIVA S.A. and ZORNOFF L.A.: Cardiac remodeling: Concepts, clinical impact, pathophysiological mechanisms and pharmacologic treatment. Arquivos brasileiros de cardiologia, (AHEAD), 2015.

6- FLACHSKAMPF F.A., SCHMID M., ROST C., ACHENBACH S., DeMARIA A.N. and DANIEL W.G.: Cardiac imaging after myocardial infarction. European Heart Journal, 32 (3): 272-83, 2011.

7- KONSTAM M.A., KRAMER D.G., PATEL A.R., MARON M.S. and UDELSON J.E.: Left ventricular remodeling in heart failure. J.A.C.C.: Cardiovascular Imaging, 4 (1): 98-108, 2011.

8- KOITABASHI N. and KASS D.A.: Reverse remodeling in heart failure-mechanisms and therapeutic opportunities. Nature Reviews Cardiology, 9 (3): 147-57, 2012.

9- GALLI A. and LOMBARDI F.: Postinfarct Left Ventricular Remodelling: A Prevailing Cause of Heart Failure. Cardiology research and practice, 2016.

10- COHN J.N., FERRARI R. and SHARPE N.: Cardiac remodeling-concepts and clinical implications: A consen- sus paper from an international forum on cardiac remodeling. Journal of the American College of Cardiology, 35 (3): $569-82,2000$.

11-LOBOZ-GRUDZIEN' K., KOWALSKA A., BRZEZINSKA B., SOKALSKI L. and JAROCH J.: Early predictors of adverse left ventricular remodelling after myocardial infarction treated by primary angioplasty. Cardiol. J., 14 (3): 238-45, 2007.

12- LANG R.M., BADANO L.P., MOR-AVI V., AFILALO J., et al.: Recommendations for cardiac chamber quantification by echocardiography in adults: An update from the American Society of Echocardiography and the European Association of Cardiovascular Imaging. Journal of the American Society of Echocardiography, 28 (1): 1-39. e14, 2015.

13-NAGUEH S.F., SMISETH O.A., APPLETON C.P., BYRD B.F., et al.: Recommendations for the evaluation of left ventricular diastolic function by echocardiography: An update from the American Society of Echocardiography and the European Association of Cardiovascular Imaging. Journal of the American Society of Echocardiography, 29 (4): 277-314, 2016

14- SAVOYE C., EQUINE O., TRICOT O., NUGUE O., et al.: Left ventricular remodeling after anterior wall acute myocardial infarction in modern clinical practice (from the REmodelage VEntriculaire [REVE] study group). The American Journal of Cardiology, 98 (9): 1144-9, 2006.

15- BOLOGNESE L., NESKOVIC A.N., PARODI G., CERISANO G., et al.: Left ventricular remodeling after primary coronary angioplasty. Circulation, 106 (18): 23517, 2002.

16- POP S., HODAŞ R., BENEDEK E., OPINCARIU D., et al.: Predictors of Left Ventricular Remodeling after Revascularized Acute Myocardial Infarction. Journal of Interdisciplinary Medicine, 1 (1): 62-70, 2016.

17- ZALIADUONYTE-PEKSIENE D., SIMONYTE S., LESAUSKAITE V., VASKELYTE J., et al.: Left ventricular remodelling after acute myocardial infarction: Impact of clinical, echocardiographic parameters and polymorphism of angiotensinogen gene. Journal of the ReninAngiotensin-Aldosterone System, 15 (3): 286-93, 2014.

18- WARREN S.E., ROYAL H.D., MARKIS J.E., GROSSMAN W. and MCKAY R.G.: Time course of left ventricular dilation after myocardial infarction: Influence of infarct-related artery and success of coronary thrombolysis. Journal of the American College of Cardiology, 11 (1): 12-9, 1988.

19- CERISANO G., BOLOGNESE L., CARRABBA N., BUONAMICI P., et al.: Doppler-derived mitral deceleration time. Circulation, 99 (2): 230-6, 1999. 


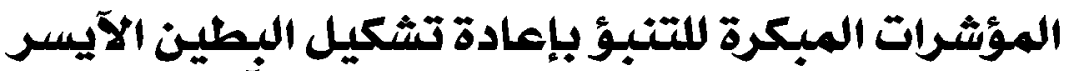

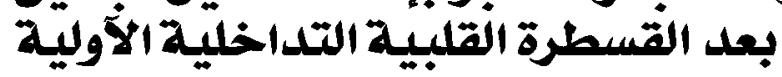

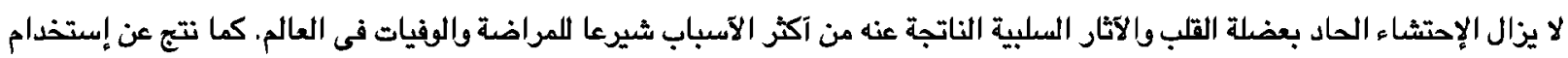

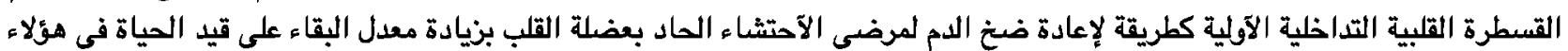

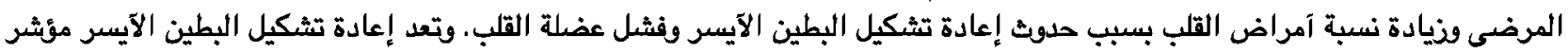
لحلوث فشل عضلة القلب ولذا تعد مؤشر سلبى لتوقع ما ستكون عليه حالة المريض.

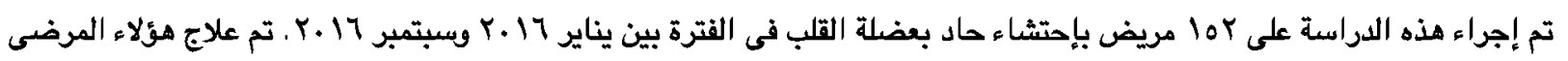

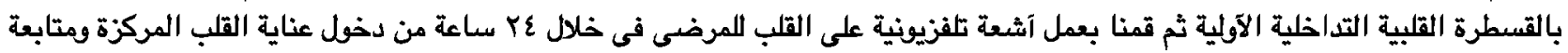

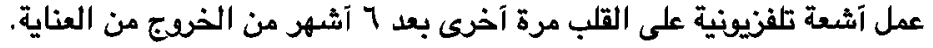

وتم تقسيم المرضى إلى مجموعتين: المجموعة الآولى التى آصيبت بإعادة تثكيل البطين الآيسر والمجموعة الثانية التى لم تصب به. وتم

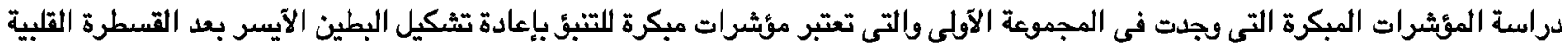
التداخلية الآولية.

كانت النتائج آن المرضى الذين يعانون من إحتشاء عضلة القلب الآمامى وإصابة الشريان التاجى الآمامى النازل ومعامل حركة جدران

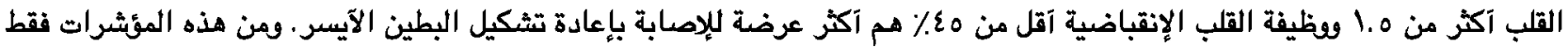

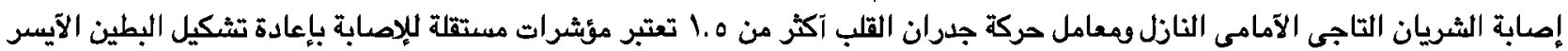
بعد القسطة القلية التداخلية الآولية.

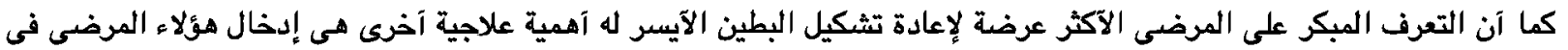

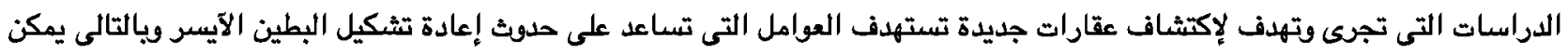
تقليل نسبة حدوثه وتقليل نسبة حدوث فشل عضلة التهل التلب. 